\title{
Business Process Modeling, Activity-Based Management, And Decision Support Systems: The Case Of B\&B Plumbing
}

Alan I. Blankley, (E-mail: blanklai@muohio.edu), Miami University, Ohio Craig E. Bain, (E-mail: craig.bain@ nau.edu), Northern Arizona University

\begin{abstract}
This case was designed to be used as a resource for professors who are interested in using decision support systems to teach activity-based management. Specifically, we developed the case for use with Hyperion Software's Activity-Based Management application, formerly called NetProphet II by Sapling Corp. Professors wishing to use this, or other activity-based management software, have trouble finding non-proprietary materials for use in teaching with the software. We developed this case to address this need.
\end{abstract}

\begin{abstract}
Although the case was designed for use with this decision-support application, its usefulness extends beyond that for two reasons. First, the case involves developing a business process model, first from a workflow, or engineering perspective, then overlaying that model with financial information to create the full business process model. The process model is developed independently of the software used to implement and run the model. The modeling process is important in itself because it focuses student attention on the nature of the work involved and interaction between work flow, resources, constraints, and costing. A natural result of developing a process model is a greater appreciation for the difficulties inherent in, and the complexity involved with, making sound managerial decisions. Second, the process model can be implemented independently of the software as well. With some effort, a spreadsheet can be used to develop the appropriate formulas, flows, factors, and units of measure based on the workflow, to carry costs down to the appropriate demands.
\end{abstract}

The case involves a plumbing firm, $B \& B$ Plumbing that has four lines of business. Based on the poor operating results of one line of business, management is considering eliminating that line, but they are not sure that the current financial results for each line are indicative of that line's true performance. Students are to develop or use the business process model for the company to assist management in making the most profitable operating decisions. They are then to evaluate the business in light of the model and its associated constraints to maximize profits.

\section{Introduction}

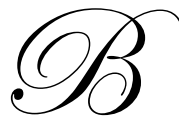

\&B Plumbing is a full-service plumbing contractor having four distinct lines of business. B\&B provides both commercial and residential plumbing, while also retailing plumbing supplies and answering service calls. The commercial line of business is widely regarded as the most profitable line in dollars. Even though revenues from the commercial line represent only $32 \%$ of total revenue, income from the commercial line is fully $63 \%$ of total net income. The service line of business is the most profitable line on a percentage basis, having an $82.7 \%$ profit margin, but revenues are relatively small from this line and not expected to grow very much over the foreseeable future. The firm earns the bulk of its revenues from its residential line. Last year the company plumbed 100 houses, generating $\$ 973,400$ in revenue. The problem is, however, that even though

Readers with comments or questions are encouraged to contact the authors via email. 
the residential jobs are relatively straightforward, requiring little variation in supplies, workmanship, or customization, the profit margins are small. Gross profit is $28 \%$, which is respectable (but still the lowest of B\&B's product lines), but the profit margin is only $0.03 \%$. Table 1 shows the company's 2000 operating performance broken out by line of business.

Table 1

B\&B Plumbing 2000 Profit and Loss Statement

Revenue

Cost of Goods Sold

Gross Profit

Overhead

Income

\begin{tabular}{lllll} 
Commercial & Residential & Retail & Service & Total \\
\hline$\$ 578,240$ & $\$ 973,400$ & $\$ 175,000$ & $\$ 100,000$ & $\$ 1,826,640$ \\
$\$ 280,000$ & $\$ 700,000$ & $\$ 106,250$ & $\$ 12,500$ & $\$ 1,098,750$ \\
\hline$\$ 298,240$ & $\$ 273,400$ & $\$ 68,750$ & $\$ 87,500$ & $\$ 727,890$ \\
$\$ 109,231$ & $\$ 273,079$ & $\$ 41,449$ & $\$ 4,876$ & $\$ 428,635$ \\
\hline$\$ 189,009$ & $\$ 321$ & $\$ 27,301$ & $\$ 82,624$ & $\$ 299,255$
\end{tabular}

Revenue

Cost of Goods Sold

Gross Profit

Overhead

Income
B\&B Plumbing 2000 Common Size P\&L

\begin{tabular}{lllll} 
Commercial & Residential & Retail & Service & Total \\
\hline $100.00 \%$ & $100.00 \%$ & $100.00 \%$ & $100.00 \%$ & $100.00 \%$ \\
$48.42 \%$ & $71.91 \%$ & $60.71 \%$ & $12.50 \%$ & $60.15 \%$ \\
\hline $51.58 \%$ & $28.09 \%$ & $39.29 \%$ & $87.50 \%$ & $39.85 \%$ \\
$18.89 \%$ & $28.06 \%$ & $23.69 \%$ & $4.88 \%$ & $23.47 \%$ \\
\hline $32.69 \%$ & $0.03 \%$ & $15.60 \%$ & $82.62 \%$ & $16.38 \%$
\end{tabular}

$\mathrm{B} \& \mathrm{~B}$ management is highly distressed at the abysmal performance of the residential line. Management is thinking of dropping the residential line, even though the bulk of the company's revenue (53\%) comes from this area. Given the bottom line, it simply doesn't make much sense to allocate resources to a line that barely breaks even. They are seriously considering moving some of the work crew over to the commercial side, and then letting some of the support staff go. What has kept them from moving out of residential altogether is the fact that the residential line is expected to grow by $15 \%$ for the next three years, while the commercial line has growth potential of only 4\%. Also, management is beginning to wonder how other plumbing contractors seem to thrive on only residential work, while they have a hard time simply becoming profitable, let alone thriving.

Before reducing the size of the firm, cutting its revenue stream in half, and laying people off, management has asked you to review the numbers to be sure they are accurate. During your investigation, you accumulate the following data:

\section{$B \& B$ 's normal overhead allocation procedures:}

Overhead is currently allocated based on each division's proportion of cost of goods sold to total cost of goods sold multiplied by the total overhead dollars. For example, the Commercial Division allocation for Overhead is $\$ 280,000 / \$ 1,098,750 \mathrm{X} \$ 428,635=\$ 109,231$ (rounded).

\section{Company Resources}

1. The company rents a 4,000 sq. ft. building which acts as its warehouse and retail store front, and provides office space for the office staff (order processing and administrative support), as well as housing the inventory for both the commercial and residential operations and the retail operations. The lease calls for annual rent of $\$ 13,000$. Insurance costs on the building are $\$ 150$ per month.

2. The company owns two trucks which it uses for deliveries. The trucks cost $\$ 53,000$ each when they were 
purchased, and have estimated useful lives of ten years. One truck is two years old, the other is four years old. The salvage value on both trucks was estimated to be $\$ 3,000$ each, and they are both being depreciated on a straight-line basis. Annual operating costs are $\$ 3,000$ each; annual insurance costs are $\$ 1,200$ per truck. Trucks are used principally for deliveries to the job sites. After examining the useage patterns, B\&B determined that an average commercial job required 3 deliveries, while an average residential job required 1 delivery. Service jobs required a delivery about once in every four calls, and the retail division used the trucks about once in every three sales. B\&B doesn't employ dedicated drivers. Usually a crew member or someone from retail or service will make the deliveries depending on the type of job, and whenever they get time. Since B\&B serves a limited geographic region, the distance between jobs or deliveries does not vary too much from the average.

Labor: The commercial division employs three full-time, and one half-time, crew members earning $\$ 16$ per hour. The commercial division sometimes has to allow its three full-time crew members to work overtime in order to stay on schedule, but it strictly limits the overtime to 5 hours per week on average. Overtime wages are time-and-a-half. The commercial crew is the only crew allowed to work overtime. The service line employs one person half-time who earns $\$ 15.75$ per hour. The retail division has one full-time person earning \$12 per hour, and the residential division employs two crew members each earning $\$ 12.50$ per hour. The Residential crew currently averages 40 hours (in total) per job. Each full time crew member has a practical working capacity of 45 hours per week. ${ }^{1}$

3. In addition, the company employs two crew chiefs, one to oversee the commercial line, the other to oversee the residential line. Each crew chief is paid a salary of $\$ 38,000$.

4. Materials: Average materials costs per job are as follows: Commercial: $\$ 17,500$; Residential: $\$ 7,000$; Retail (average cost per sale): \$85; Service: $\$ 125$.

5. Office Support: There are two areas of support for the various plumbing operations. Order processing provides support by receiving orders, negotiating the exact nature of the plumbing needs with customers, identifying the materials requirements for the jobs, quoting prices, and so forth. Administrative support (called "Admin") handles various other administrative tasks, such as arranging schedules, returning calls, bookkeeping, scheduling vendor deliveries, and other logistical or office management tasks. There is one full-time Admin who earns $\$ 22,500$ per year, and three full-time order processors also earning $\$ 22,500$ per year. In addition, each order processor also requires about $\$ 200$ per year of supplies to perform his or her job effectively.

6. Inventory Management: One employee handles inventory management. This job function requires that the employee retrieve the required parts for the various jobs (commercial, residential, and retail), and then load the trucks (commercial and residential jobs) with parts and supplies according to the order and materials lists prepared by the order processing group. With these duties, as well as the occasional delivery, the inventory manager takes about six minutes per pick on average. For retail sales, the inventory manager retrieves the parts and conveys them to the retail desk in the front of the building. The inventory manager earns $\$ 24,000$ per year.

\section{Other Relevant Information}

1. Utility costs for the company's building runs .067 per Kilowatt Hour $(\mathrm{kWh})$. The company anticipates that they will use 46,045 $\mathrm{kWh}$ this year.

2. The building is used approximately as follows: Inventory management takes up 3400 square feet of space; while Admin Support takes up 100 square feet; Order Processing, 350 square feet; and the Retail Desk, 150 square feet.

3. Since Order Processing is an important function for ensuring that jobs are completed according to the customer orders, taking and processing orders is a relatively time consuming task. All orders are not processed the same. Some orders, particularly the commercial orders, are complex, requiring the order processing people to look up item numbers and availability, develop purchase orders for out-of-stock items,

\footnotetext{
${ }^{1}$ On certain occasions, residential crew members put in overtime hours but are not compensated with overtime pay like the commercial crew. Because management believes that the division is barely profitable, it is not willing to discuss overtime arrangements with the residential crew. It has signaled that if the residential division ever becomes more clearly profitable, it will offer overtime pay to the crew. As a result, the residential crew chief can count on about 45 hours per week out of the crew.
} 
and so forth. As a result, it takes all three order processors a little more than a week to process one commercial order. The average commercial order has 1,500 lines on it. The average residential order has 150 lines. The average retail order will have 3 lines on it, and the average service order has four lines.

4. This year, the company worked on 16 commercial jobs, which, on average, generated $\$ 36,140$ in revenue per job. The company also worked on 100 residential jobs, which brought in average revenue of $\$ 9,734$ per job. The 100 service jobs provided, on average, $\$ 1,000$ in revenue per job, while each of the 1,250 retail sales orders this year provided an average of $\$ 140$ per sale in revenue.

5. The company's basic vacation policy is two weeks paid vacation per year for salaried employees, and two weeks unpaid vacation for hourly employees.

6. Admin and Order Processing employees have a practical work week of 35 hours. The employees actually are present 40 hours per week, but you determine that, after considering trips to the coffee machine, interruptions and the like, a full work week is 35 hours.

7. The employee who staffs the retail desk takes, on average, $1 / 2$ hour per sale. This employee has a practical working capacity of 35 hours per week.

8. On average, an order processor can process about 10 order lines per hour.

9. On average, the Admin support person spends about 22 hours per commercial job, 6.1 hours per residential job, .21 hours per retail sale, and 5.25 hours per service job.

10. Inventory management costs are allocated based on the number of inventory picks performed by the inventory manager. On average, commercial jobs require 450 picks, residential requires 45 picks, retail requires 3 picks, and service jobs require 4 picks. The inventory manager, like the office staff, has a practical work week of 35 hours.

Required:

Question 1: Prepare a complete business process model of the operations of B\&B Plumbing. First develop the operational model, then draw the schematic to represent that model. Finally, overlay the financial data and information on the operational schematic to create the complete business process model.

Question \#2: Using the business process model you've developed, determine what the profit is for each line of business, as well as overall profitability. How do these compare to the profit picture from the company's P\&L presented above? Which division is the most profitable? Which is next most profitable? Why are the costs shifted from one division to another? Is this a more accurate representation of the profit makeup by division? Why?

Question \#3: How many more commercial jobs can the company undertake before it realizes a broken constraint? What is the first constraint that gets broken? How would you address this constraint?

Question \#4: Assuming that you can solve this constraint, how many additional commercial jobs can be undertaken before violating another constraint?

Question \#5: Investigate two alternative ways of alleviating the constraint. What is the best way (i.e., most profitable way) to alleviate the existing constraint? What happens to profit if the company adopts your suggestion?

Question \#6: Now assume that B\&B added one more commercial job (for a growth rate of $6.25 \%$ and a total of 17 commercial jobs) and also grew the residential line of business by $10 \%$ (accepted 110 residential jobs). Assume the admin has a practical working capacity of $40 \mathrm{hrs}$ per week. What happens to profits?

Question \#7: What resource or activity has the lowest utilization rate? What would you recommend to improve this rate? (Continue to allow the Admin a 40 hour practical work week, but reset all other settings. Also do not count the Commercial Crew Overtime supply, which will have a utilization rate of zero.)

Question \#8: Remove the retail line of business and all costs associated only with retail. Reallocate associated occupancy costs to Admin support. What does eliminating the retail line of business do to profitability? 
Question \#9: Reset all parameters to the beginning values. What is the maximum realistic profit you can develop without introducing any new resources? Use any combination of revenue or cost reduction that is reasonable.

\section{Teaching Notes}

This case is best used with Hyperion Activity Based Management software (formerly Sapling Corporation's NetProphet II). Hyperion Corporation has a standard approach to building the operational and financial business process models which it calls the "Model Approach." It differs from typical activity-based costing approaches by first focusing on the operations of the company, then applying the financial amounts to the operational model.

By using a process-modeling approach that focuses on the flow of work through an enterprise, the software allows the modeling of costs, activities, and processes within the business, while also recognizing physical or operational constraints. The software supports an iterative decision process of evaluating multiple business scenarios and comparing alternatives to improve business performance. Not only does it enable decision-makers to develop what-if scenarios quickly, it also supports the evaluation of the operational and financial impact of various production and management strategies.

\section{Classroom Use}

We have used this case in both undergraduate and graduate accounting information systems courses. It has direct applicability to Managerial, Cost, or Advanced Cost accounting courses as well. Our treatment of the case differs between undergraduate and graduate students in that we do not require the undergraduates to develop the process model on their own. Generally, our approach has been to provide the completed business process model to the undergraduates while requiring the graduate students to develop it from the data provided. The undergraduates are then required to use the software to run scenarios and answer the rest of the questions. The graduate students develop their own models, implement the models in the application, then run scenarios. The principle reason for this different is that we allot more time and depth to the concept of process modeling to the graduate class.

Generally, the case leads to excellent class discussion, both on the case itself - What should B\&B do? What is their maximum profit potential given certain decisions?, and the like - and on the usefulness of the decision tool itself. Many students see for the first time how complex certain decisions are, and the software allows them to make trade-offs, change assumptions or estimates, then see the likely results of their decisions.

The nature of assignments can vary as well. We require graduate students to present and defend their models and results. The assigned approach is that the students are taking on the persona of the accountant for B\&B, and the instructor is the president. Students have to convince the president of the particular course of action they propose. After presentations, the class discusses and compares results, then the students turn in a report containing the model and written answers to the questions for further evaluation. We also spend some time in discussion with the undergraduate sections, who turn in written answers to the questions as well.

\section{Solutions to Questions}

Question 1: Prepare a business process model of the operations of $B \& B$ Plumbing. First develop the operational model, then draw the schematic to represent that model. Finally, overlay the financial data and information on the operational schematic to create the complete business process model.

This question asks students to develop both the operational model and the financial model underlying the business process. This step is the most important step, and the most difficult. In order to make the modeling process more accessible, we now provide some basic information on the process.

Accordingly, the first step in employing Hyperion's business process model approach is to determine the operational flow through the business. In diagramming the operational flow, the model uses six basic diagramming 
symbols.
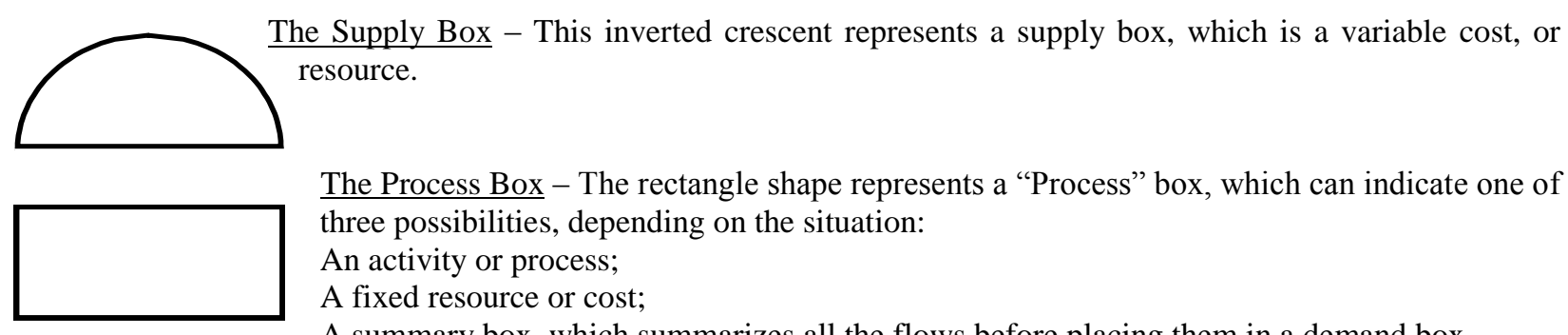

The Process Box - The rectangle shape represents a "Process" box, which can indicate one of three possibilities, depending on the situation:

An activity or process;

A fixed resource or cost;

A summary box, which summarizes all the flows before placing them in a demand box

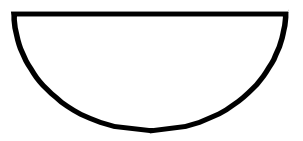

The Demand Box - Demand boxes represent the ultimate goal of the process, and may be products, lines of business, customers, and so forth.

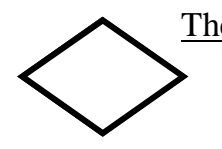

The Route Box - This diamond shape represents a decision point or a routing point in a process. It may be used, for example, to indicate whether regular or overtime wages are to be paid.

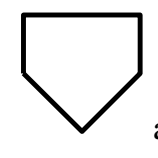

Out Connector - This symbol connects out from a supply or process box and represents data that leads into a corresponding "In Connector." Connectors are used in order to prevent the diagram from appearing too cluttered or confusing.

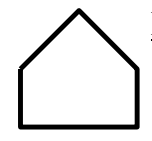

In Connector - This symbol connects into a process box. It is always the input to a box leading from the corresponding "Out Connector" symbol.

Hyperion's methodology for model development begins with creating an operational model from the bottom up; that is, the developer starts with the demands, then progresses to the resources and activities directly supporting those demands, then to the second level of resources or activities supporting those first level activities or resources, and so forth until the entire work flow has been captured. Once the operational model has been developed, then the financial data are applied to the model from a top-down approach. That is, beginning with the highest level activity or resource, the developer will apply costs to each resource or activity, ultimately ending by applying the revenue estimates to the demand.

The overall model operational schematic for B\&B Plumbing is presented in Figure 1. This schematic represents the work flow for $B \& B$ plumbing. Utiltities are a variable resource consumed by the building (Occupancy), which itself is a resource supporting four activities: admin, order processing, inventory management, and the retail desk. With the exception of the retail desk, these activities as well as the delivery trucks and the crew chiefs, support the commercial and residential demands. Thus, the commercial demand (in other words, commercial jobs, since each line of business forms the demand) is supported by two fixed resources: the crew chiefs and the trucks. Commercial demand is also supported by three activities: admin, order processing, and inventory management. Each of these activities are, in turn, supported by the occupancy resource, which itself requires a variable resource (utilities) for operation.

To portray the workflow, we model the resources and activities supporting each demand flowing into summary boxes, which then flow directly with a single link to the appropriate demand. The variable resources, direct labor and direct materials, support the residential demand. Since the commercial division allows some overtime, we treat the normal wages as a fixed resource (they effectively become fixed by the job since overtime is 
necessary) and the overtime wages as a variable resource. Both of these feed into a route box, which itself is connected to the commercial summary. With the exclusion of the crew chiefs and the overtime choice, the same resources and activities also support retail and service demands. The retail desk is an additional inflow into the retail summary box. The operational schematic illustrates the overall workflow for B\&B.

In order to model the financial flows, we overlay the financial data on the operational model. Figure 2 shows the completed business process model for the commercial and residential divisions. The commercial demand box identifies the volume - there are 16 commercial jobs throughout the year - and the anticipated revenue per job: $\$ 36,140$. Direct materials, a variable cost, is expected to be $\$ 17,500$ per job. In general, the costs associated with a resource or activity are listed to the left of the box, and are allocated based on the appropriate units of measure, which are identified in the small rectangles directly underneath the various boxes. For example, utilities costs run \$0.067 per kilowatt hour. The dollar amount per unit (\$0.067) is identified to the left of the utilities supply box, and the unit of measure $(\mathrm{KwHr})$ is identified directly beneath it. These costs are then accumulated based on the rate times the volume. In this case, the cost would be $.067 * 46,045 \mathrm{KwHr}$ for a total of $\$ 3,085$.

Figure 1

Business Process Model of B\&B's Work Flow

(Operational Schematic)

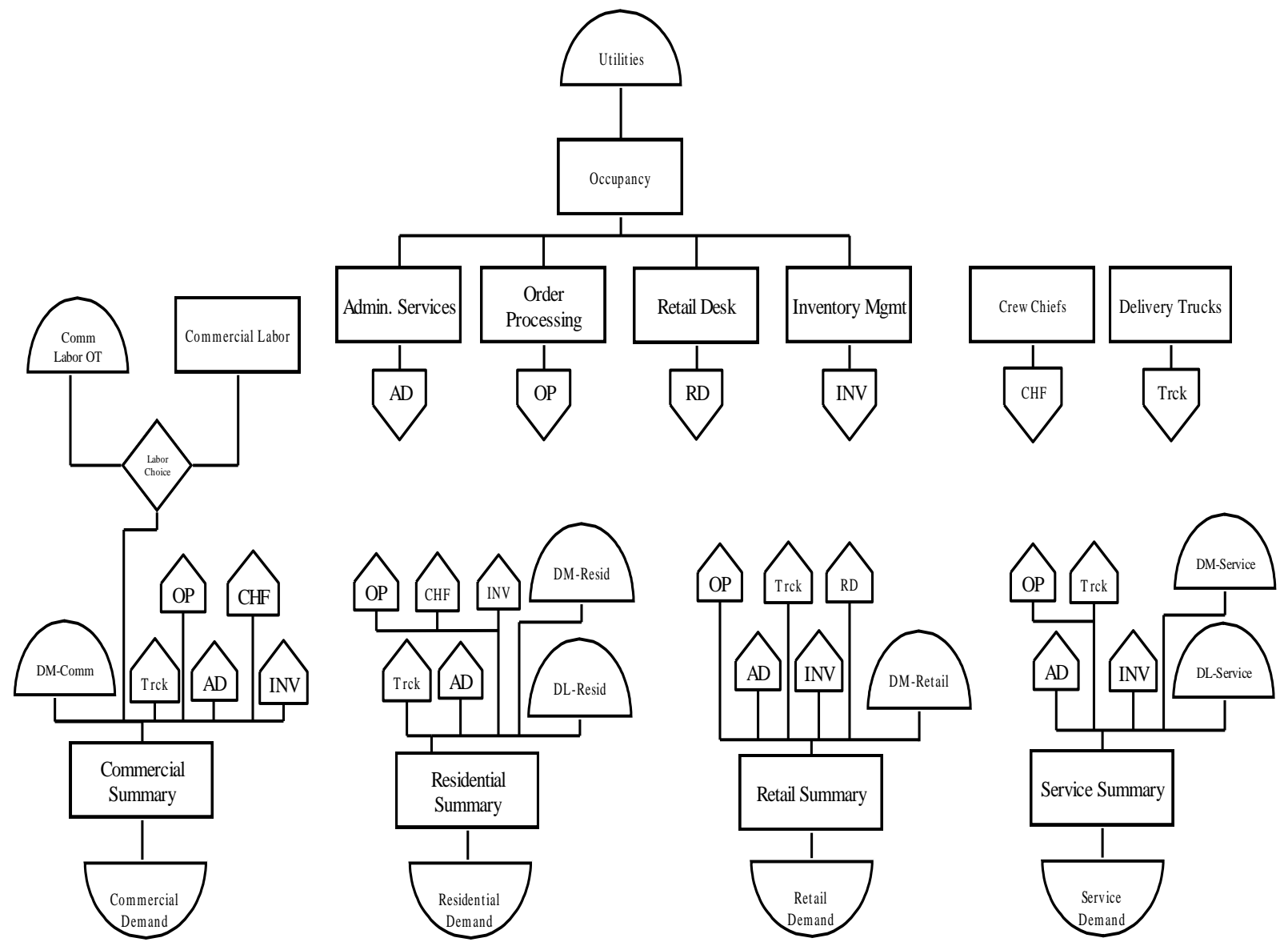


More specifically, the expense - the .067 per KwHr is then allocated to the resource or activity beneath it in the model based on a "factor," applied by the unit of measure. Factors may be either "constant" or "unit." Constant factors will allocate a cost based on a set percent or amount. The utilities costs, for example, are allocated to the occupancy resource based on a constant factor of $100 \%$ (or 46,045) since the utility costs do not apply to other buildings. Likewise, the occupancy costs are allocated based on a constant factor of square footage. These costs are allocated to admin services (100 sq. ft.), order processing (350 sq. ft.), retail desk, (150 sq. ft.), and inventory management ( 3,400 sq. ft.) based on the amount of space each activity consumes.

Unit factors, on the other hand, allocate costs based on the number of units of input consumed for a given unit of output. For example, the order processing department, on average, processes 1,500 order lines for each commercial job. The unit factor is therefore 1,500 (1,500 lines / 1 job). We place the unit factor designation next to the input connector box that designates that activity. The average admin support per commercial job is 22 hours, so the unit factor is 22 (22 admin hrs/ 1job). Unit factors are always calculated as input/output. Note that the unit factor for the commercial division's truck cost is 3 - that is, 3 deliveries per job. Deliveries are the units of measure for trucks; jobs are the unit of measure for commercial demand. Thus the factor between them will always be calculated as deliveries per job. Table 2 lists the factors for each particular box in the model.

Note that to the right of many boxes there is a rounded square containing information regarding the practical constraint on that resource or activity. The admin services process box, for example, has a constraint of $\mathrm{V}=35, \mathrm{M}=\# A d m i n * \# W k s$, which indicates that the practical working capacity of the Admin Sercvices department is 35 hours per week multiplied by the number of Admins multiplied by the number of weeks in the year. Thus the practical working capacity of Admin services is 1,750 hours $(1 \mathrm{admin} * 35 \mathrm{hrs} /$ week $* 50$ weeks). The reason the constraint is identified in this fashion is to allow the model enough flexibility to add more Admin employees if need be. Figure 3 presents the completed business process models for the retail and service lines of business.

Question \#2: Using the business process model you've developed, determine what the profit is for each line of business, as well as overall profitability. How do these compare to the profit picture from the company's $P \& L$ presented above? Which division is the most profitable? Which is next most profitable? Why are the costs shifted from one division to another? Is this a more accurate representation of the profit makeup by division? Why?

This is clearly the principal issue in the case. Allocating costs using the business process model rather than the company's crude cost allocation method reveals that while net profit remains the same, the profitability picture of each line of business changes dramatically. Figure 4 displays the results as presented by NetProphet. The commercial line still remains the most profitable on an absolute dollar basis, but more importantly the residential line proves to be contributing far more to profitability than the company's P\&L indicates. Residential is actually contributing $\$ 107,411$ to profits, equivalent to approximately $36 \%$ of the firm's total profit. Under the model, the residential line's profit margin is $11 \%$, vastly different from the $0.03 \%$ from the firm's common-size P\&L. In fact, the recalculated profit margins are commercial $-19 \%$; Residential $-11 \%$; Retail $-10 \%$; and Service $-63 \%$. The residential line's profitability appears dramatically different than what it looked like under the standard approach. As a percent of sales, it is now greater than retail. The other lines all appear less profitable than they had previously appeared due to the more accurate overhead allocations within the model. Eliminating the residential line, as management is considering, would be a disaster. 
Figure 2

Completed Business Process Model of B\&B's Work Flow Commercial \& Residential Divisions
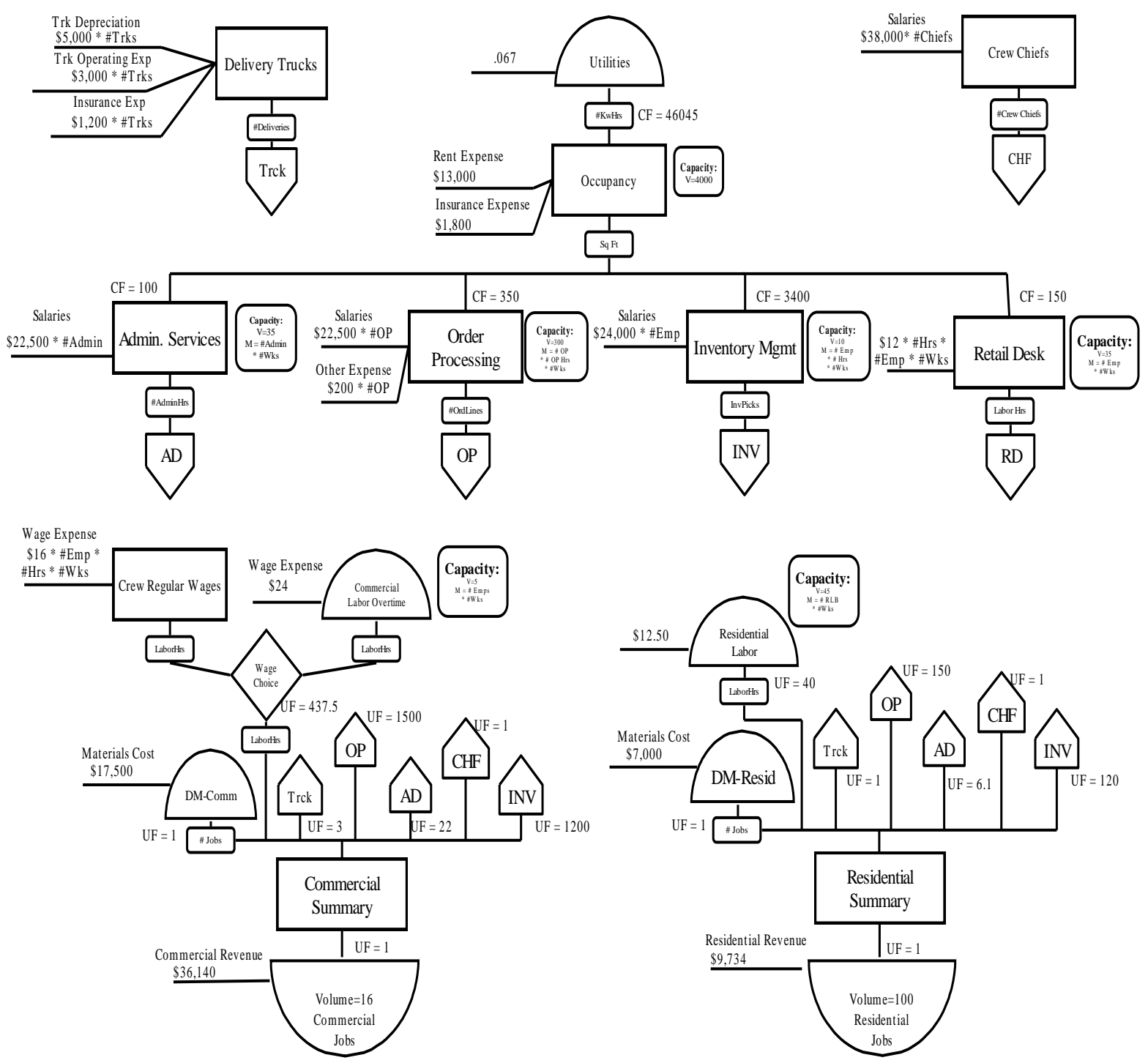
Table 2

Factors Used in the Financial Model for B\&B Plumbing

\begin{tabular}{|c|c|c|}
\hline Box & Factor Type & Factor Value \\
\hline \multicolumn{3}{|l|}{ Commercial } \\
\hline Direct Materials & Unit & 1 \\
\hline Truck & Unit & 3 \\
\hline Admin Support & Unit & 22 \\
\hline Order Processing & Unit & 1,500 \\
\hline Inventory Management & Unit & 1,200 \\
\hline Wage Choice & Unit & 437.5 \\
\hline Crew Chiefs & Unit & 1 \\
\hline \multicolumn{3}{|l|}{ Residential } \\
\hline Direct Materials & Unit & 1 \\
\hline Direct Labor & Unit & 40 \\
\hline Truck & Unit & 1 \\
\hline Admin Support & Unit & 6.1 \\
\hline Order Processing & Unit & 150 \\
\hline Inventory Management & Unit & 120 \\
\hline Crew Chiefs & Unit & 1 \\
\hline \multicolumn{3}{|l|}{ Retail } \\
\hline Direct Materials & Unit & 1 \\
\hline Retail Desk & Unit & .5 \\
\hline Truck & Unit & .333 \\
\hline Admin Support & Unit & .21 \\
\hline Order Processing & Unit & 3 \\
\hline Inventory Management & Unit & 3 \\
\hline \multicolumn{3}{|l|}{ Service } \\
\hline Direct Materials & Unit & 1 \\
\hline Direct Labor & Unit & 10 \\
\hline Truck & Unit & .25 \\
\hline Admin Support & Unit & 5.25 \\
\hline Order Processing & Unit & 4 \\
\hline Inventory Management & Unit & 4 \\
\hline \multicolumn{3}{|l|}{ Non-Division Specific } \\
\hline Occupancy to Admin Support & Constant & 100 \\
\hline Occupancy to Order Processing & Constant & 350 \\
\hline Occupancy to Inventory Mgmt & Constant & 3400 \\
\hline Occupancy to Retail Desk & Constant & 150 \\
\hline Utilities & Constant & 46,045 \\
\hline
\end{tabular}




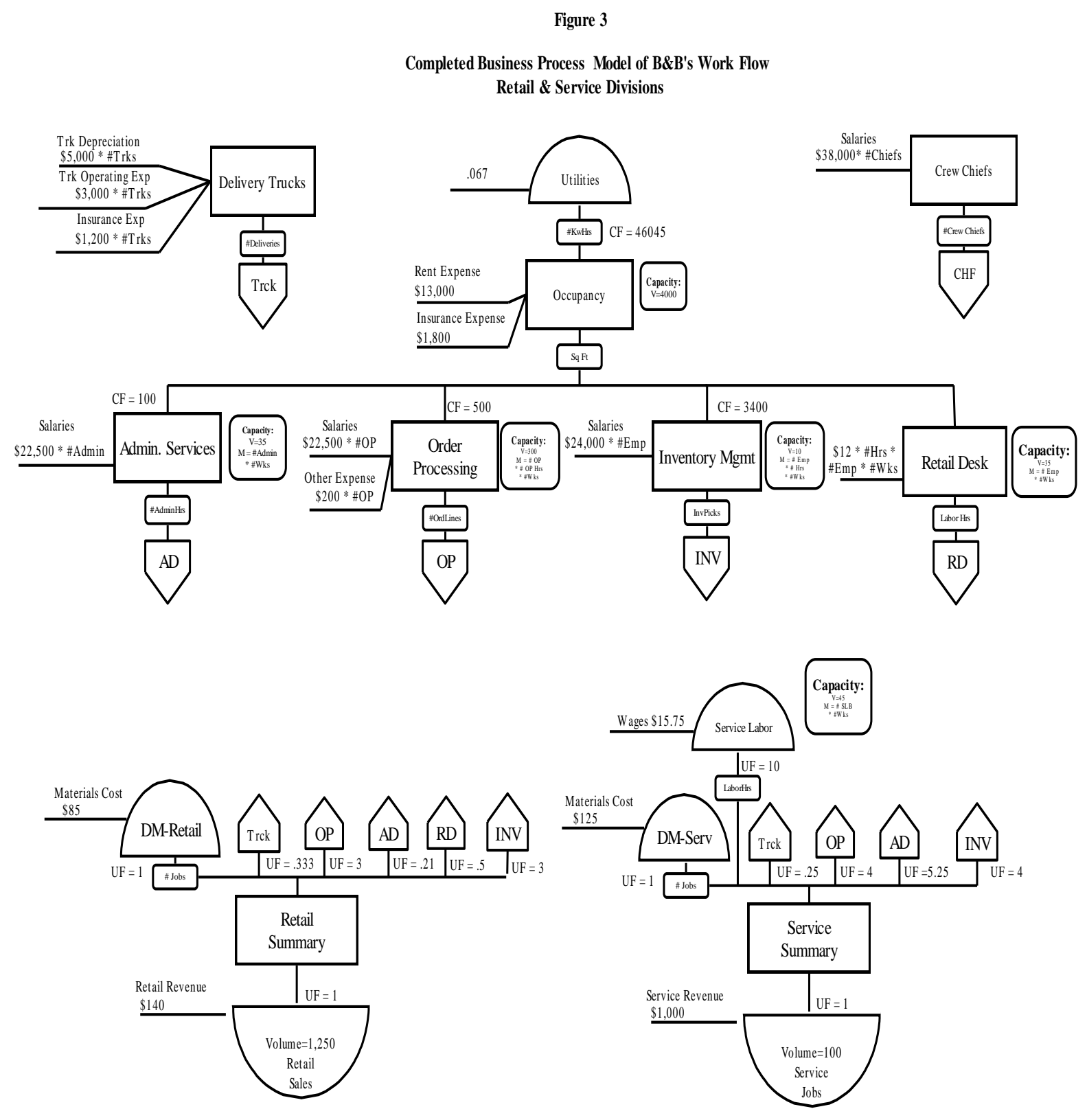


Figure 4

Model Financial Results

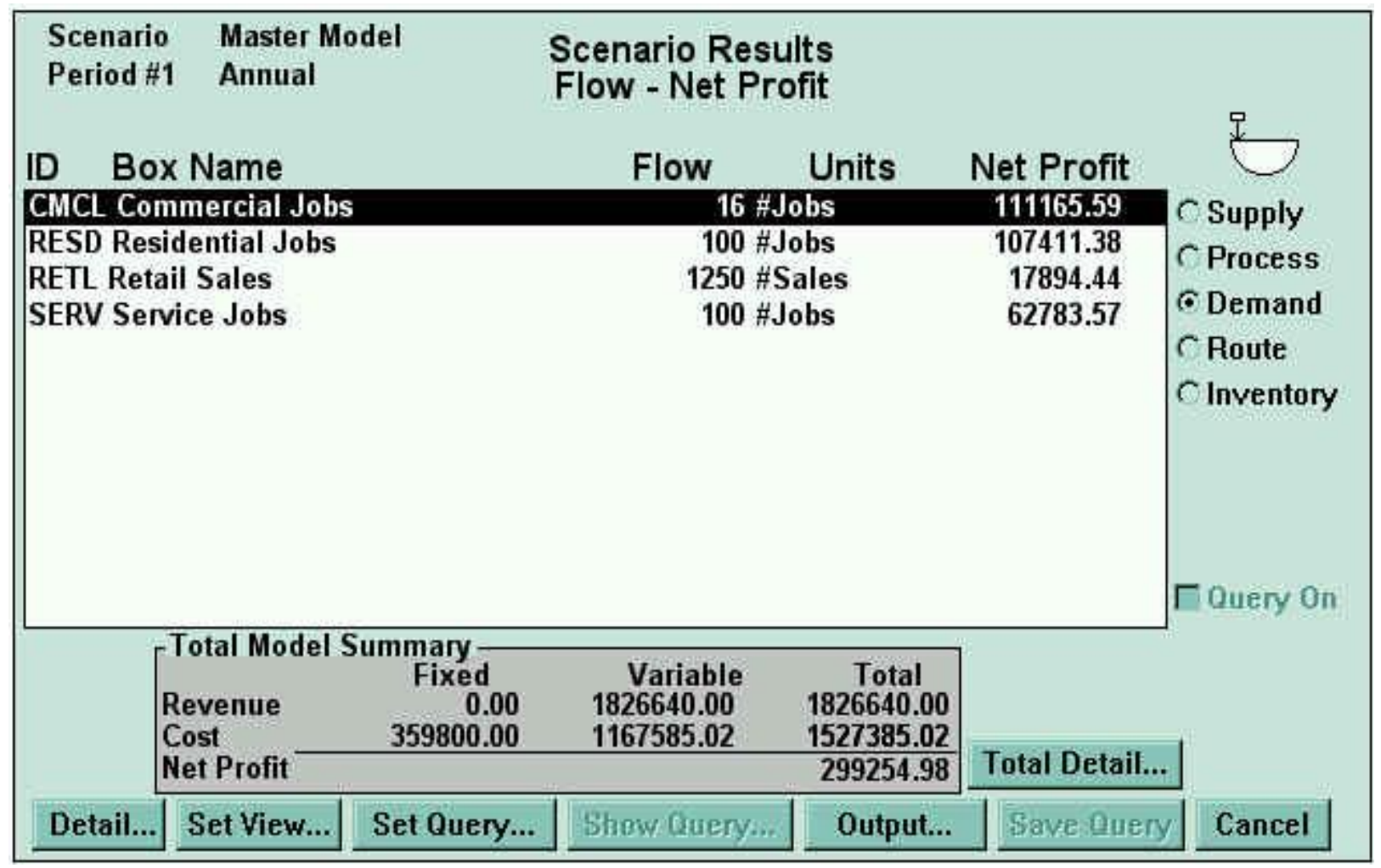

The reason the result obtains is that the residential line had been bearing the greatest share of overhead costs due to B\&B's crude cost allocation policy. In effect, it has been subsidizing the other lines of business, making them look more profitable than they really were. Because it represents a line of business with relatively standard production activities and uncomplicated supporting activities, it had been shouldering many of the costs (like the order processing costs, for example) that more correctly belonged to the other lines of business. When each line bears its appropriate share of the costs, the profitability picture becomes clearer, and which decision to take becomes obvious.

Question \#3: How many more commercial jobs can the company undertake before it realizes a broken constraint? What is the first constraint that gets broken? How would you address this constraint?

Answering this question requires using the scenario-playing capabilities in the software. Given the company's existing resources and policies (limiting commercial crew overtime to 5 hours per week), the company cannot add any additional jobs without violating a constraint. If it accepts an additional job, then the admin will need to work 21.5 hours above what has been identified as the maximum practical number of hours ( 35 hours per week). See Figure 5. If the company expects to grow, clearly it will have to address this constraint. Note that prior to adding the job, the admin is already at $100 \%$ of capacity $(1,749.5$ hours out of 1750 practical working capacity). 
Figure 5

First Broken Constraint for Commercial Line

:Play Scenarios

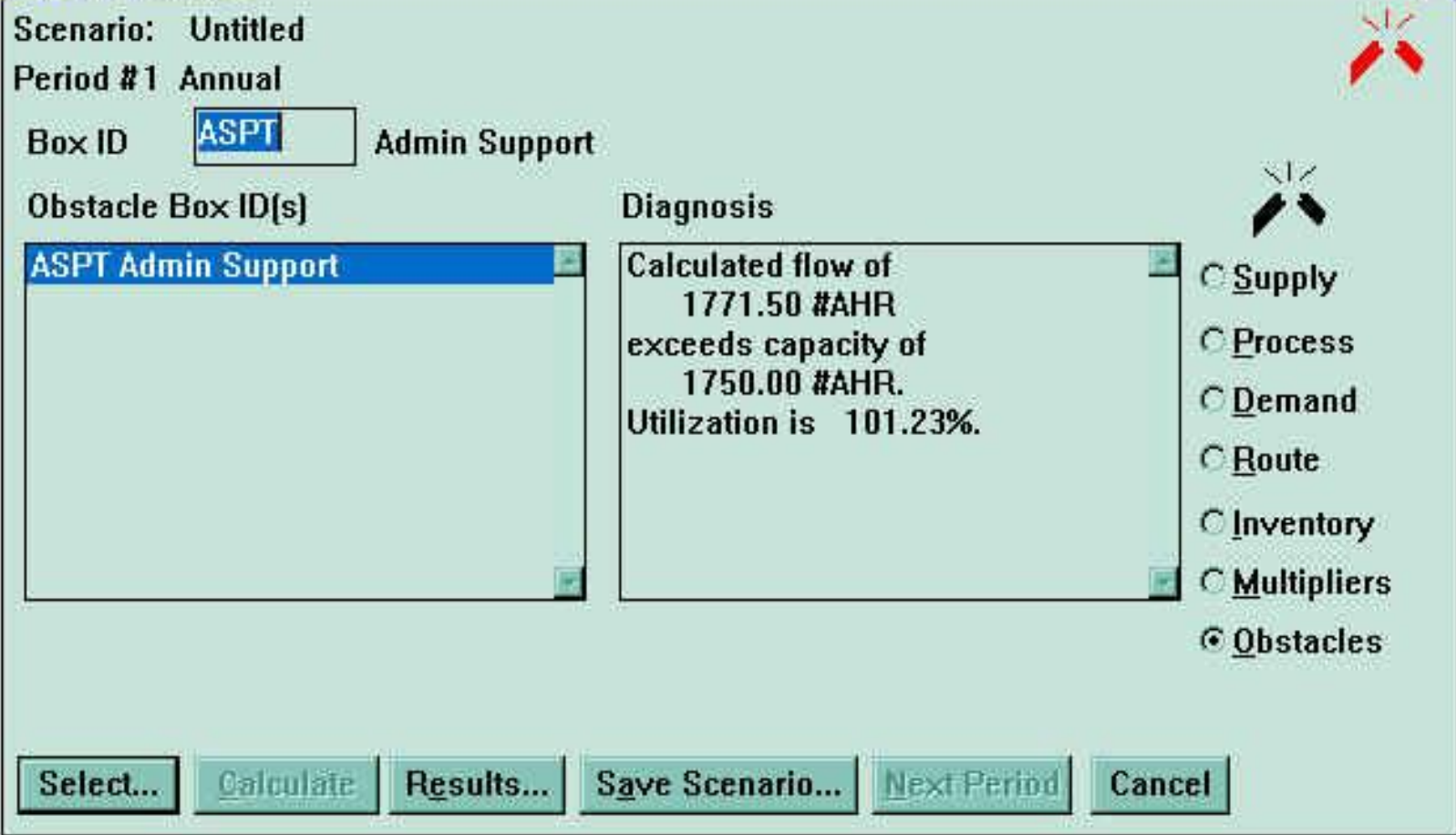

The easiest way to address the constraint is to increase the practical work week of the admin to 40 hours per week. Making this assumption and then allowing for one additional commercial job increases profit to $\$ 307,395$. At this point, however, it is useful to stress that while this is an easy solution from a scenario-playing view, it is difficult to implement in practice because it requires a $15 \%$ increase in productivity out of the admin. $\mathrm{B} \& \mathrm{~B}$ could also hire another admin, either full or part-time, or it could allow overtime. Each of these solutions will require additional costs. By trying different solutions and then comparing the profitability results for each solution (scenario) students get a feel for the trade-offs inherent in managers' decisions. At this point, students typically develop a deep appreciation for the software, because it allows them to make well-informed decisions.

Question \#4: Assuming that you can solve this constraint, how many additional commercial jobs can be undertaken before violating another constraint?

In order to solve the admin constraint, we set the Admin work hour constraint to 40, rather than 35 . This is the simplest solution, but probably not the most realistic as discussed above. For the sake of investigating the next constraint conveniently, we choose the simplest solution. To the extent that students choose another solution (like overtime), the results will differ because the software will take account of the increased costs associated with the decision. After solving this constraint, the company can accept one additional commercial job. On the 18th job, however, B\&B will face yet another broken constraint, identified in Figure 6. The commercial crew would need to work a total of 7,875 hours to meet the demand, but can only work 7,000 regular hours (3.5 crew members * 40 hrs/week * 50 weeks) and 750 overtime hours ( 3 full-time crew members * 5 allowable hours $* 50$ weeks), leaving a shortfall of 125 labor hours. 
Figure 6

Second Constraint for Commercial Jobs

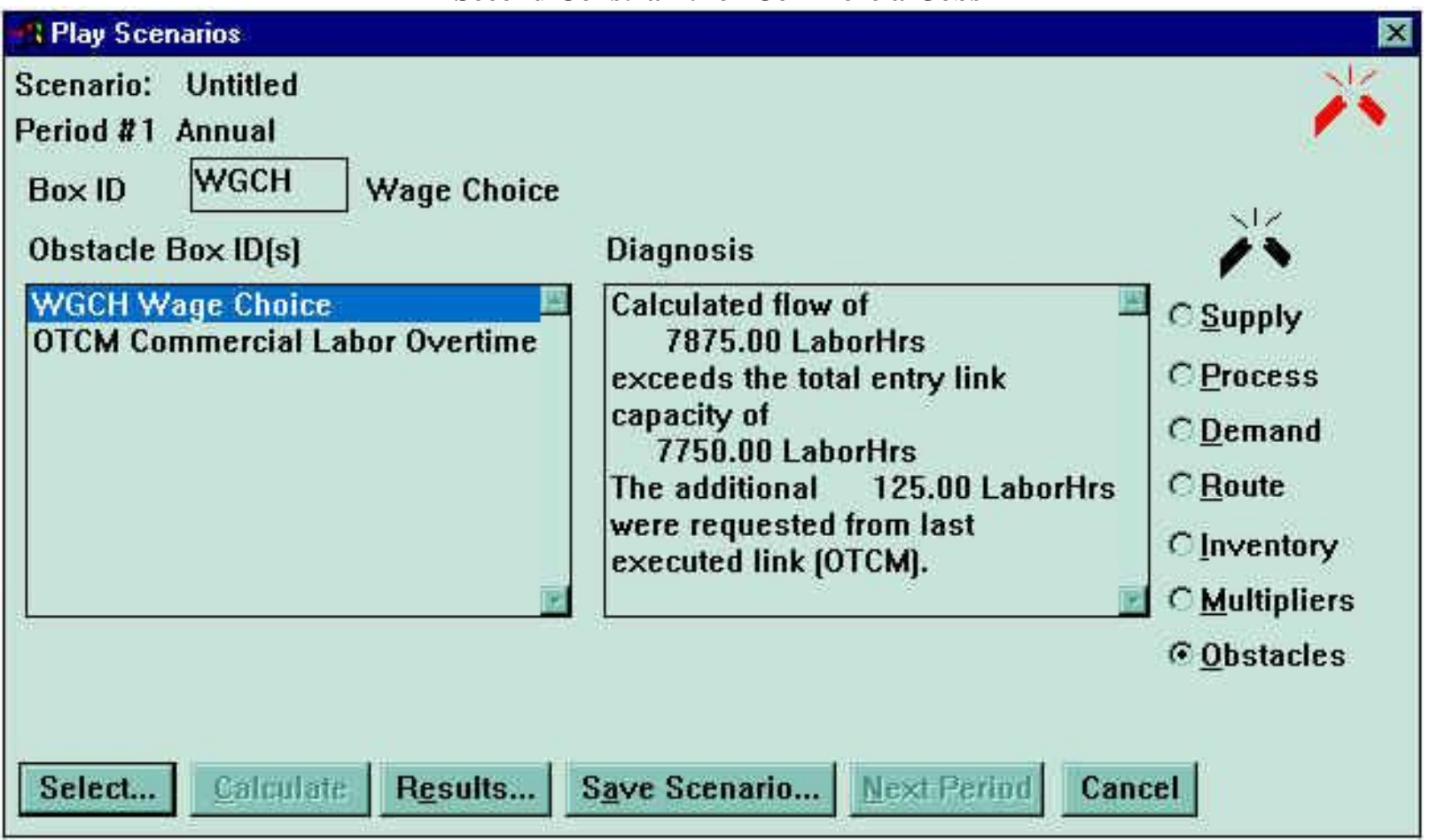

Question \#5: Investigate two alternative ways of alleviating the constraint. What is the best way (i.e., most profitable way) to alleviate the existing constraint? What happens to profit if the company adopts your suggestion?

There are two potential ways of addressing the constraint. The least costly way is to increase the half-time person to full-time. If this person goes full-time (change the multiplier on the Crew Wages process box to 4 from $3.5)$, then labor costs increase to $\$ 128,000$, but no overtime becomes necessary. With eighteen commercial jobs, total firm profit increases to $\$ 320,535$.

The second alternative is to relax the overtime policy (On the Commercial Labor Overtime supply box, change the constraint from 5 to, say, 10). If B\&B allowed 10 OT hours per week, then firm profit would increase to $\$ 315,535$-- $\$ 5,000$ lower than the first alternative.

Question \#6: Now assume that B\&B added one more commercial job (for a growth rate of $6.25 \%$ and a total of 17 commercial jobs) and also grew the residential line of business by 10\% (accepted 110 residential jobs). Assume the admin has a practical working capacity of 40 hrs. per week. What happens to profits?

Total profits grow to $\$ 329,735$. See Figure 7 for a breakdown of dollar profit by line of business. In this scenario, the residential line would now contribute approximately $39 \%(\$ 127,558)$ of the firm's dollar profits. 
Figure 7

Results for 17 Commercial Jobs and 110 Residential Jobs

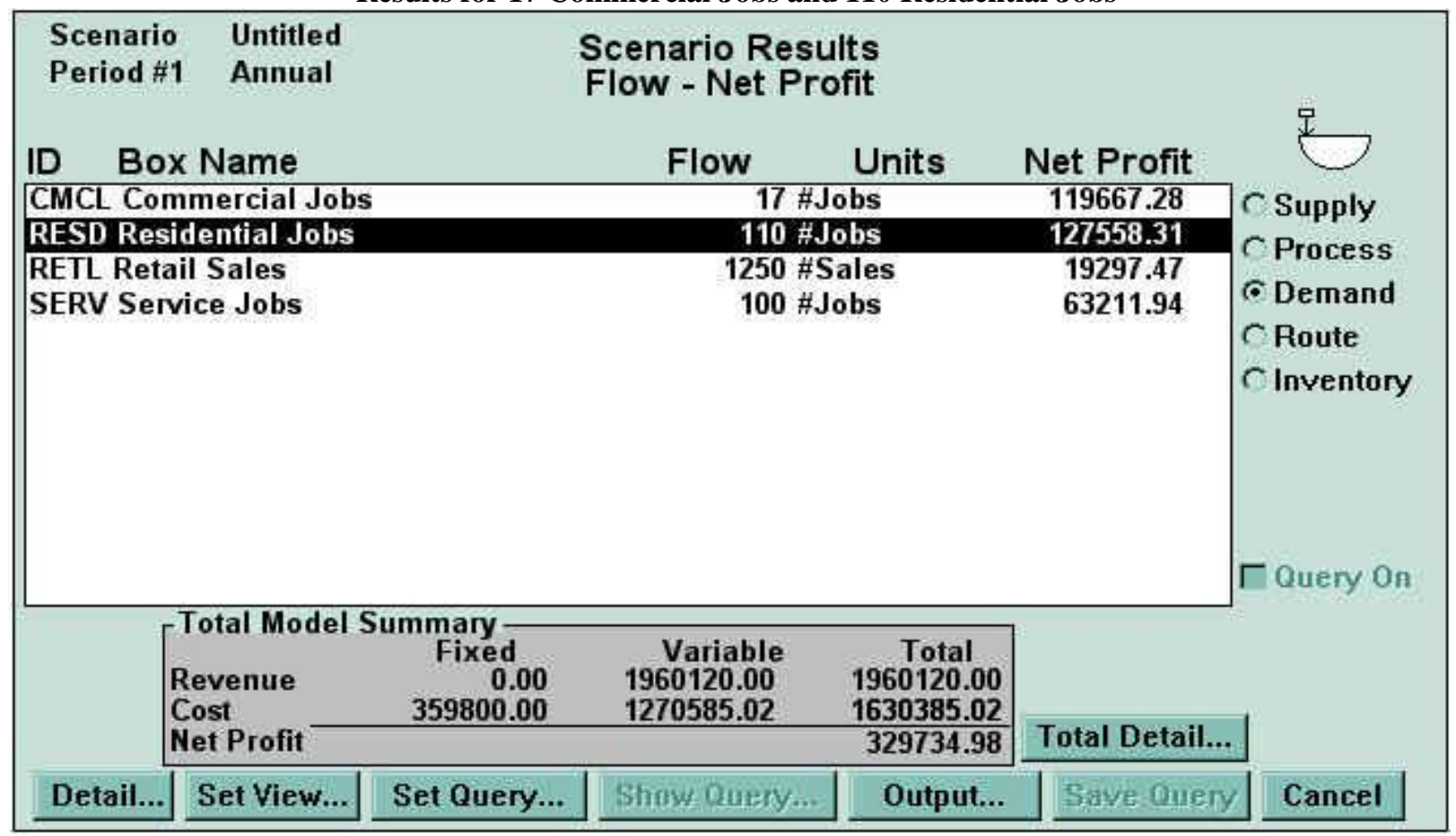

Question \#7: What resource or activity has the lowest utilization rate? What would you recommend to improve this rate? (Continue to allow the Admin a 40 hour practical work week, but reset all other settings. Also do not count the Commercial Crew Overtime supply, which will have a utilization rate of zero.)

Students can find the utilization rate of any resource or activity by playing scenarios and examining all boxes having constraints attached to them. At the current production level of 16 commercial jobs and 100 residential jobs, the constraints will be as listed below:

$\begin{array}{ll}\text { Resource or Activity } & \text { Utilization Rate } \\ \text { Admin Support } & 87.5 \% \\ \text { Order Processing } & 82.2 \% \\ \text { Inventory Management } & 90.6 \% \\ \text { Commercial Crew Wages } & 100.0 \% \\ \text { Residential Direct labor } & 88.9 \% \\ \text { Service Direct Labor } & 100.0 \% \\ \text { Retail Desk } & 35.7 \%\end{array}$

Utilization rates indicate that the retail desk manager is under-utilized, with a rate of only $35.7 \%$ at current volumes of retail sales.

Improving the productivity of the retail desk is difficult because the retail desk must be manned when open, and sales are unpredictable. Customers like the predictability and reliability of normal retail hours. Some possible solutions are to lower the retail hours to half-time and reduce the hours of the retail manager as well or else use the retail manager in another capacity half-time (possibly as a second half-time person in commercial labor, which would serve to alleviate that constraint without necessitating overtime). The problem with this approach is that customers may not care for reduced retail hours. Also, the retail manager might not be suited to the plumbing work required of crewmembers.

A second alternative might be to investigate ways to increase retail sales. Are there any programs or products that might boost the firm's sales and make more efficient use of this resource as a result? A third possibility might be to investigate eliminating the retail line and associated costs from the firm's lines of business. 
Question \#8: Remove the retail line of business and all costs associated only with retail. Reallocate associated occupancy costs to Admin support. What does eliminating the retail line of business do to profitability?

We remove the cost and revenue effects of the retail line by playing a new scenario then setting all cost, revenue, and factor amounts associated with retail to zero. Figure 8 indicates that overall profitability drops from $\$ 299,255$ to $\$ 254,505$, a reduction of $\$ 44,750$ (about $15 \%$ ).

\section{Figure 8}

Results After Dropping Retail, Eliminating Direct Retail Costs, and Reallocating Occupancy Space

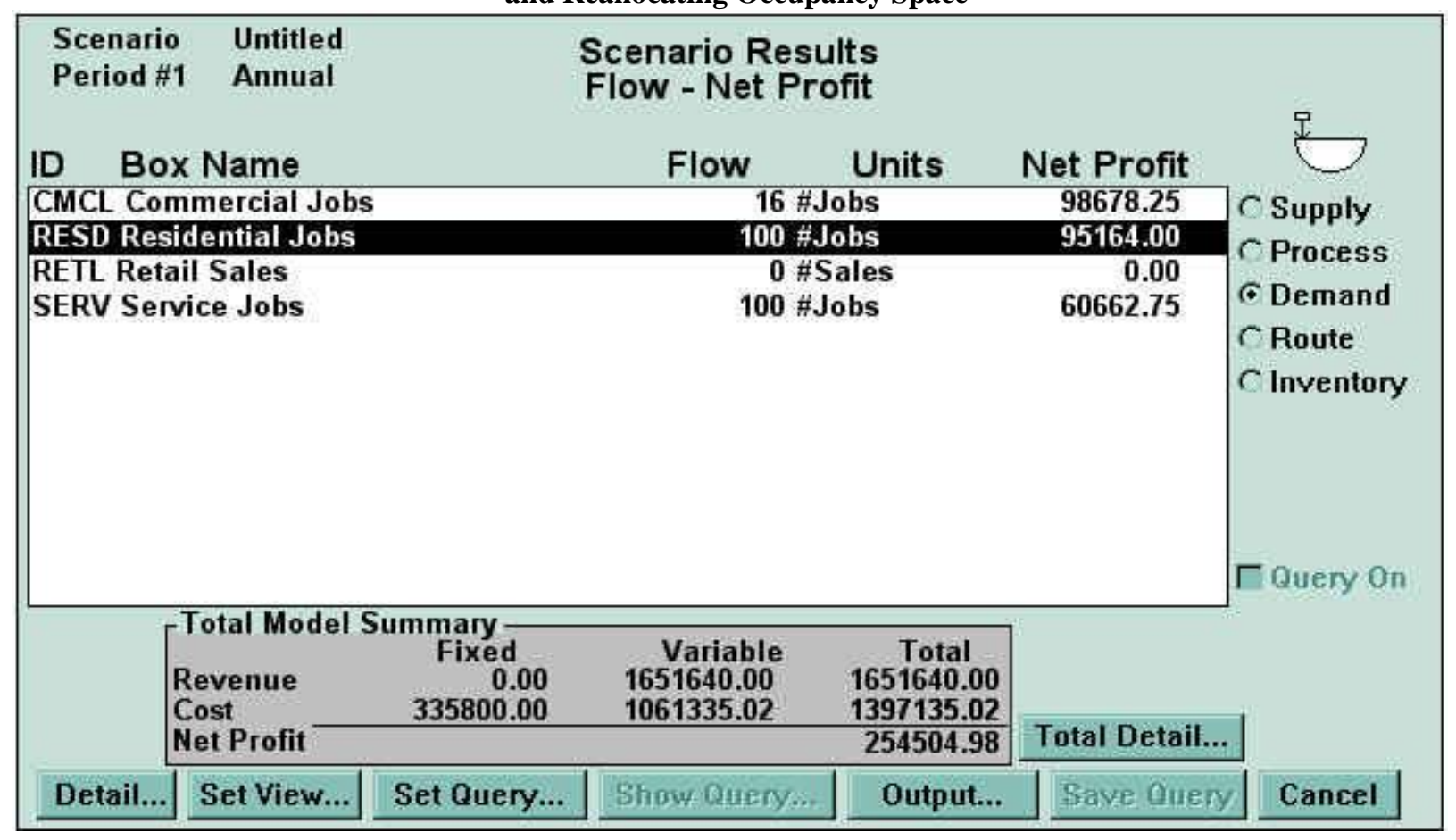

Although the original profitability of the retail line was approximately $\$ 17,894$, the reduction in overall profitability after eliminating the line of business is $\$ 44,750$ because there is no retail revenue to absorb the fixed costs associated with occupancy, admin support, inventory management, the truck, and so forth. These costs are merely reallocated. This serves to underscore the fact that a company can't reduce costs merely by eliminating activities; it must eliminate resources to lower costs. It is now apparent that eliminating the retail line in order to remove the inefficiency associated with the $35.7 \%$ utilization rate of the retail manager would be a poor response to the problem. It also comes as something of a surprise to students that a poorly performing division, product line, customer or the like often contributes a great deal to profitability by utilizing and absorbing fixed costs.

Question \#9: Reset all parameters to the beginning values. What is the maximum realistic profit you can develop without introducing any new resources? Use any combination of revenue or cost reduction that is reasonable.

This is a very open ended question designed to give students the opportunity to try different scenarios to achieve maximum profits. The only requirement is that cost reductions and revenue increases be reasonable - that is, achievable. Students enjoy working on this question; it becomes a challenge to them to try to maximize profits. 


\section{Conclusion}

This case uses a business process modeling approach in conjunction with an activity-based management DSS to introduce students to operational and financial decision-making involving a small plumbing contractor. The case is useful for accounting information systems classes, as well as managerial and cost accounting courses.

The case is also flexible. Beyond those issues discussed in the case questions, instructors can use it to investigate growth in residential, retail, or service lines. The cost assumptions and operational resources and activities necessary to add another line of business - like an electronic commerce web site for the firm - can also be investigated. Once the model is established and implemented, many different operational and financial questions can be addressed, and instructors will be able to tailor the case to fit their particular needs. 
Table 1

B\&B Plumbing

2000 Profit and Loss Statement

\begin{tabular}{llllll} 
& Commercial & Residential & Retail & Service & Total \\
\cline { 2 - 6 } Revenue & $\$ 578,240$ & $\$ 973,400$ & $\$ 175,000$ & $\$ 100,000$ & $\$ 1,826,640$ \\
Cost of Goods Sold & $\$ 280,000$ & $\$ 700,000$ & $\$ 106,250$ & $\$ 12,500$ & $\$ 1,098,750$ \\
Gross Profit & $\$ 298,240$ & $\$ 273,400$ & $\$ 68,750$ & $\$ 87,500$ & $\$ 727,890$ \\
Overhead & $\$ 109,231$ & $\$ 273,079$ & $\$ 41,449$ & $\$ 4,876$ & $\$ 428,635$ \\
Income & $\$ 189,009$ & $\$ 321$ & $\$ 27,301$ & $\$ 82,624$ & $\$ 299,255$
\end{tabular}

B\&B Plumbing

2000 Common Size P\&L

Revenue

\begin{tabular}{lllll} 
Commercial & Residential & Retail & Service & Total \\
\hline $100.00 \%$ & $100.00 \%$ & $100.00 \%$ & $100.00 \%$ & $100.00 \%$ \\
$48.42 \%$ & $71.91 \%$ & $60.71 \%$ & $12.50 \%$ & $60.15 \%$ \\
\hline $51.58 \%$ & $28.09 \%$ & $39.29 \%$ & $87.50 \%$ & $39.85 \%$ \\
$18.89 \%$ & $28.06 \%$ & $23.69 \%$ & $4.88 \%$ & $23.47 \%$ \\
\hline $32.69 \%$ & $0.03 \%$ & $15.60 \%$ & $82.62 \%$ & $16.38 \%$
\end{tabular}

Table 2

Factors Used in the Financial Model for B\&B Plumbing

\begin{tabular}{lll}
\hline Box & Factor Type & Factor Value \\
\hline Commercial & & \\
Direct Materials & Unit & 1 \\
Truck & Unit & 3 \\
Admin Support & Unit & 22 \\
Order Processing & Unit & 1,500 \\
Inventory Mangement & Unit & 1,200 \\
Wage Choice & Unit & 437.5 \\
Crew Chiefs & Unit & 1 \\
Residential & & \\
Direct Materials & Unit & 1 \\
Direct Labor & Unit & 40 \\
Truck & Unit & 1 \\
Admin Support & Unit & 6.1 \\
Order Processing & Unit & 150 \\
Inventory Management & Unit & 120 \\
Crew Chiefs & Unit & 1 \\
Retail & & \\
Direct Materials & Unit & 1 \\
Retail Desk & Unit & .5 \\
Truck & Unit & .333 \\
Admin Support & Unit & .21 \\
Order Processing & Unit & 3 \\
Inventory Management & Unit & 3
\end{tabular}


Service

Direct Materials

Direct Labor

Truck

Admin Support

Order Processing

Inventory Management

Non-Division Specific

Occupancy to Admin Support

Occupancy to Order Processing

Occupancy to Inventory Mgmt

Occupancy to Retail Desk

Unit

Unit

1

Utilities

Unit $\quad .25$

Unit $\quad 5.25$

Unit 4

Unit 4

Constant $\quad 100$

Constant $\quad 350$

Constant $\quad 3400$

Constant $\quad 150$

Constant 46,045 
Figure 1

Business Process Model of B\&B's Work Flow

(Operational Schematic)
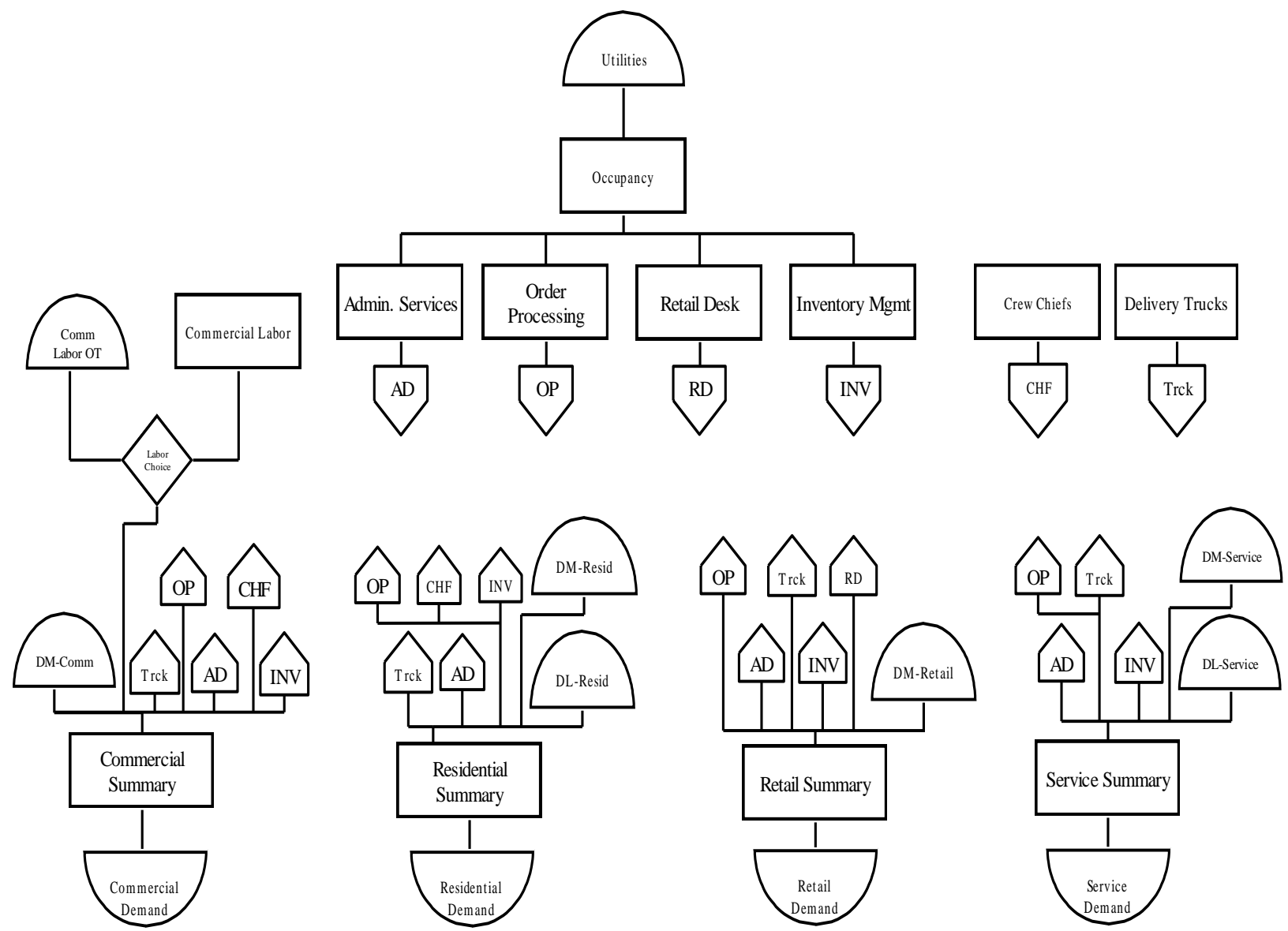
Commercial \& Residential Divisions
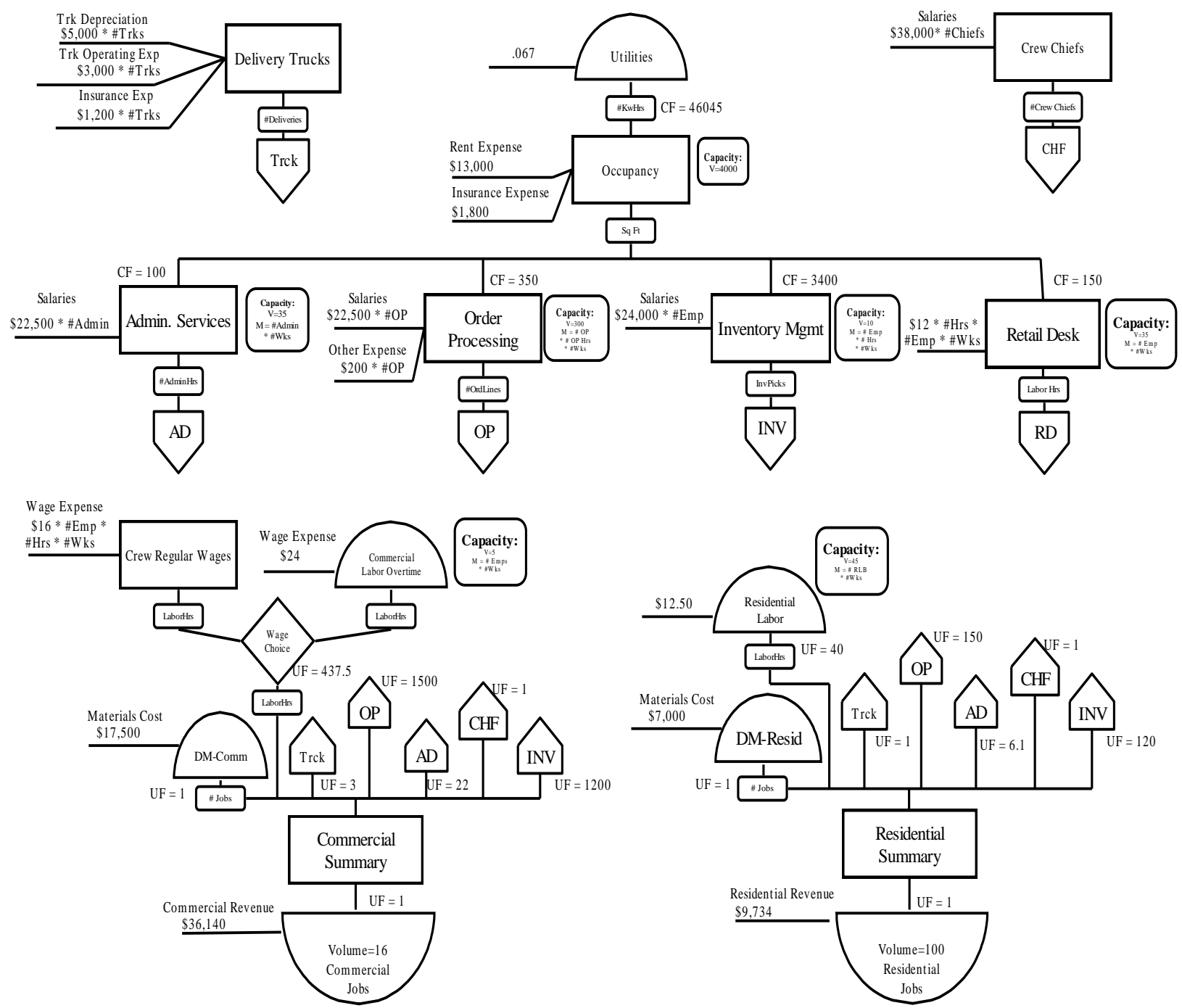
Figure 3

The Review of Business Information Systhiffsted Business Pracess Model of B\&B's Work Flow Volume 6, Number 3 Retail \& Service Divisions
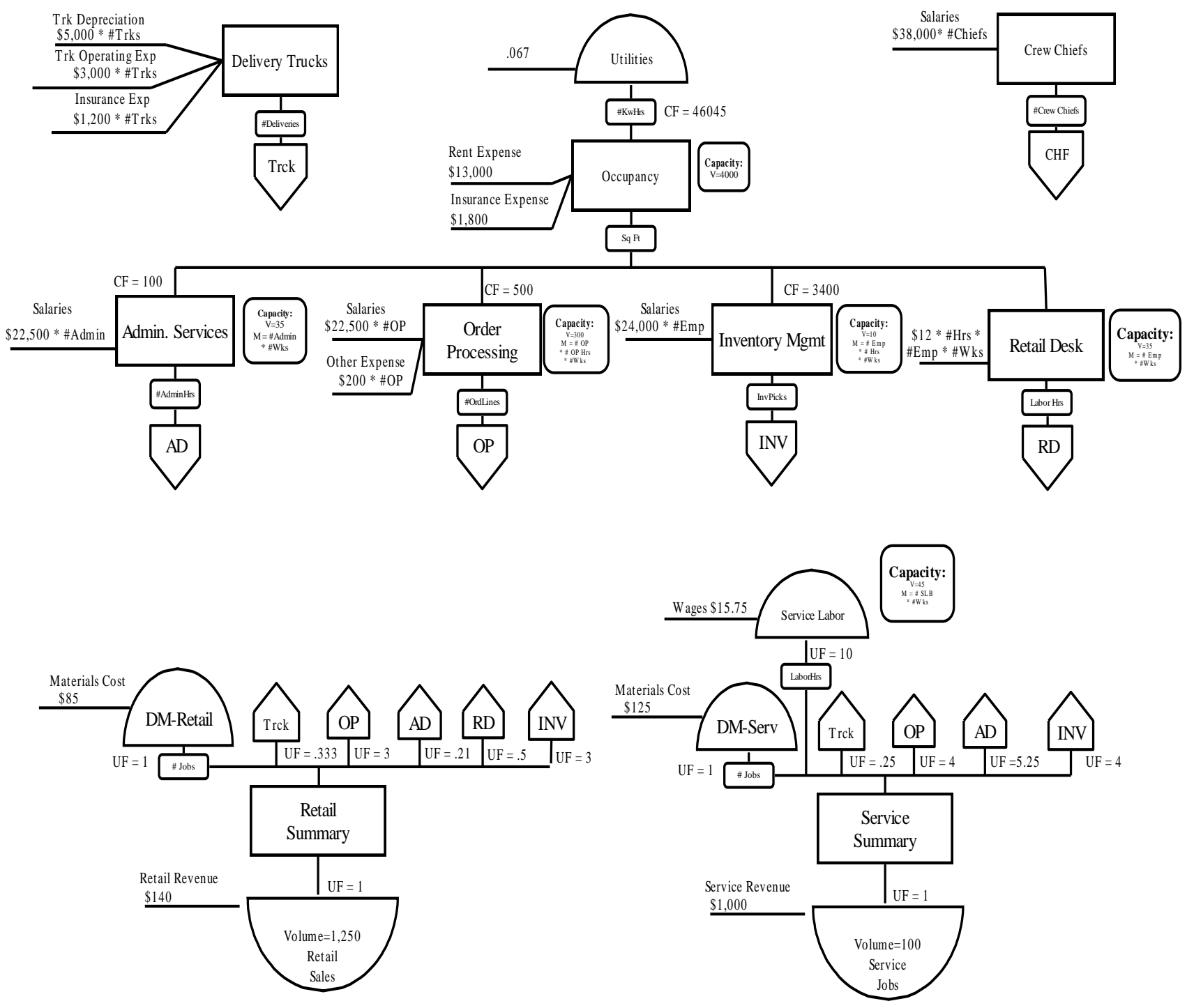
Figure 4

Model Financial Results

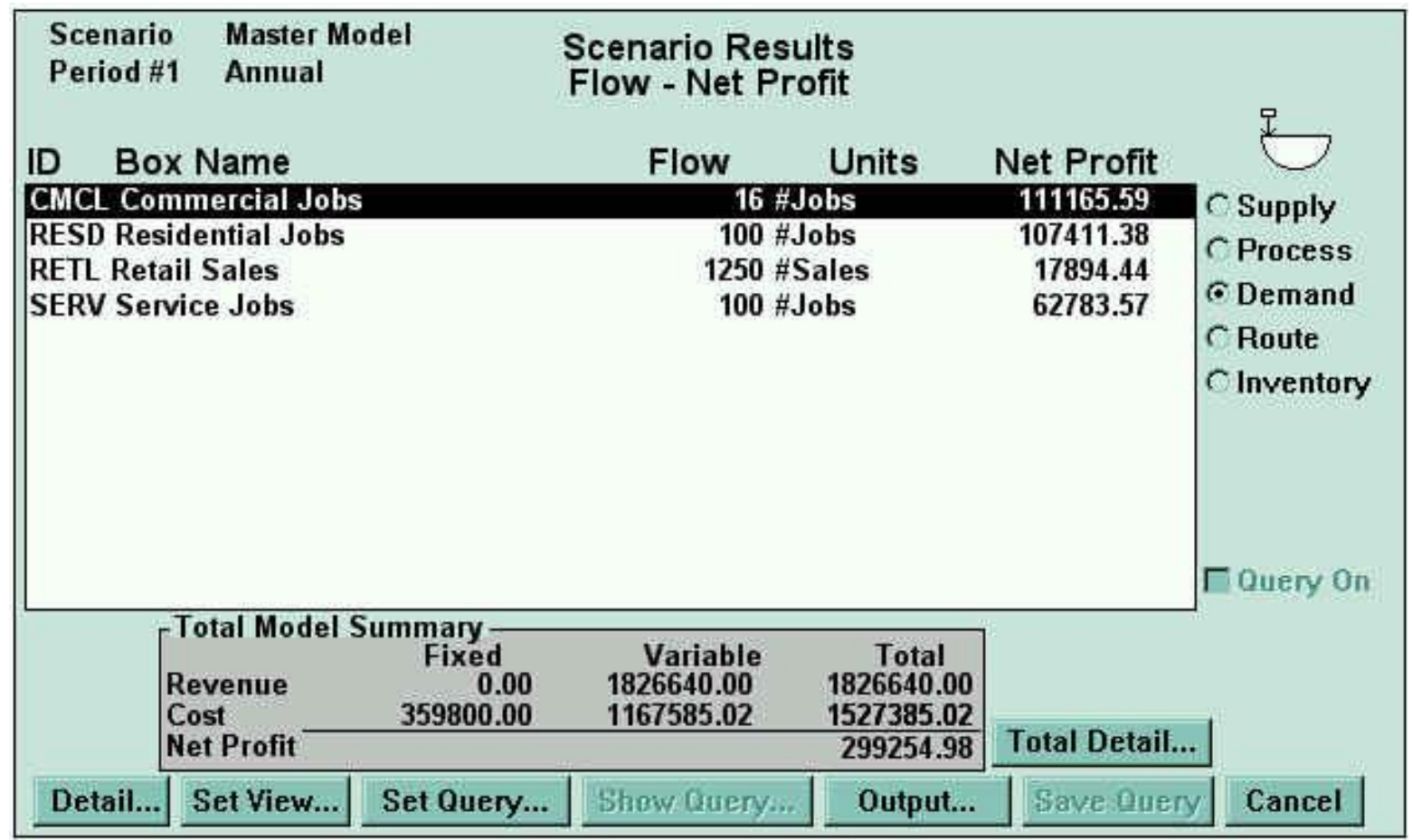




\section{Figure 5}

First Broken Constraint for Commercial Line

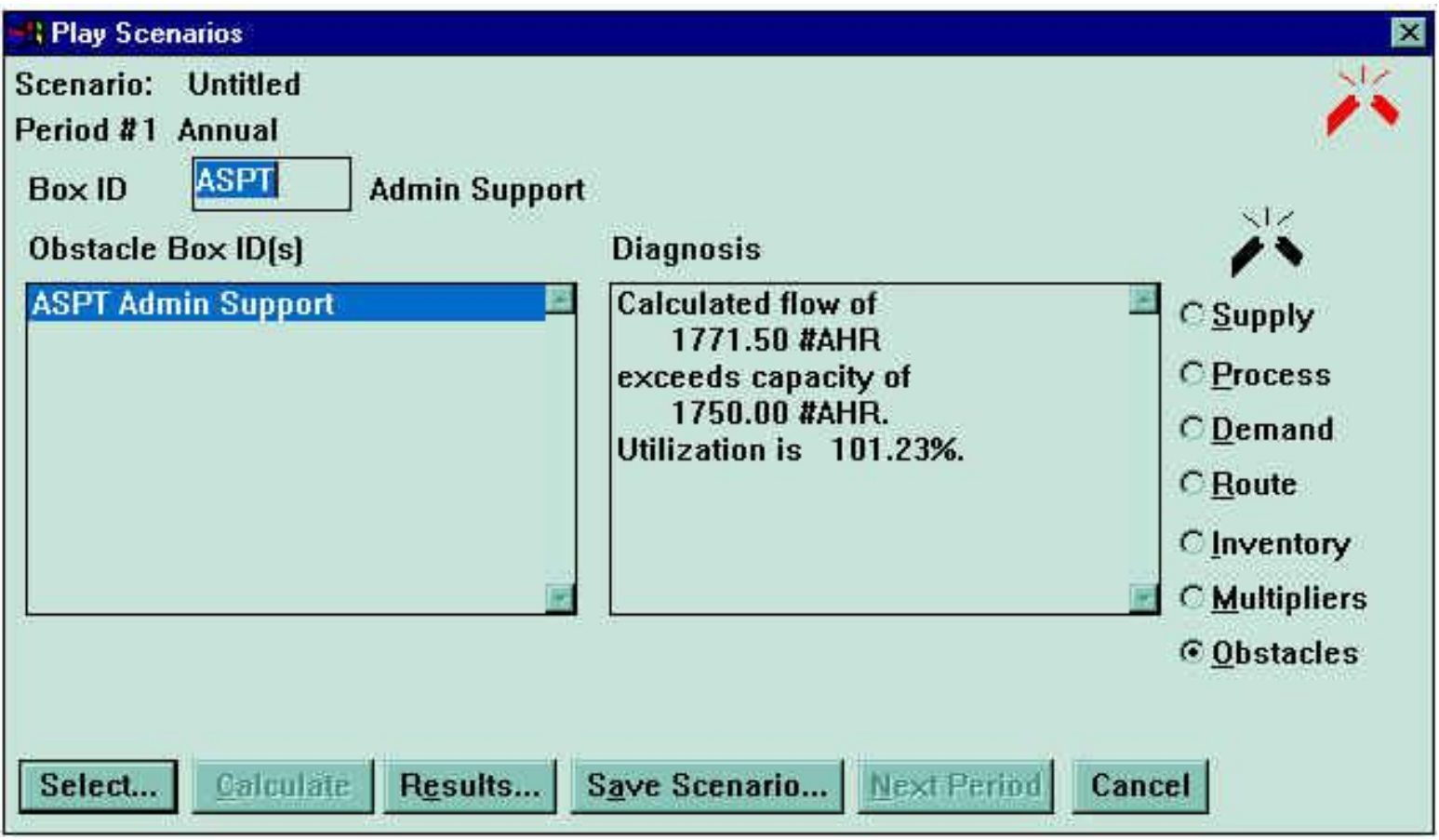


Figure 6

Second Constraint for Commercial Jobs

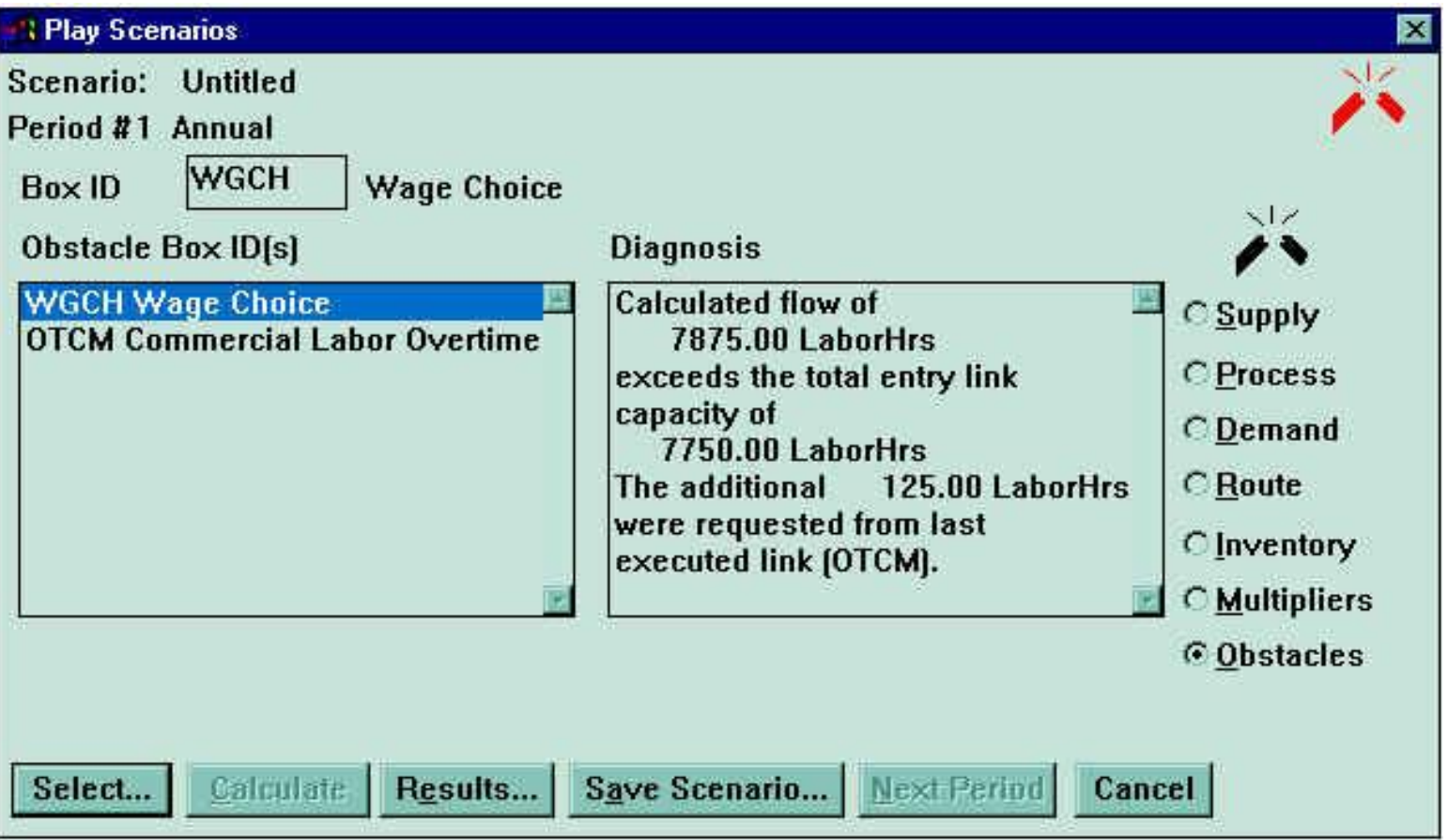


Figure 7

Results for 17 Commercial Jobs and 110 Residential Jobs

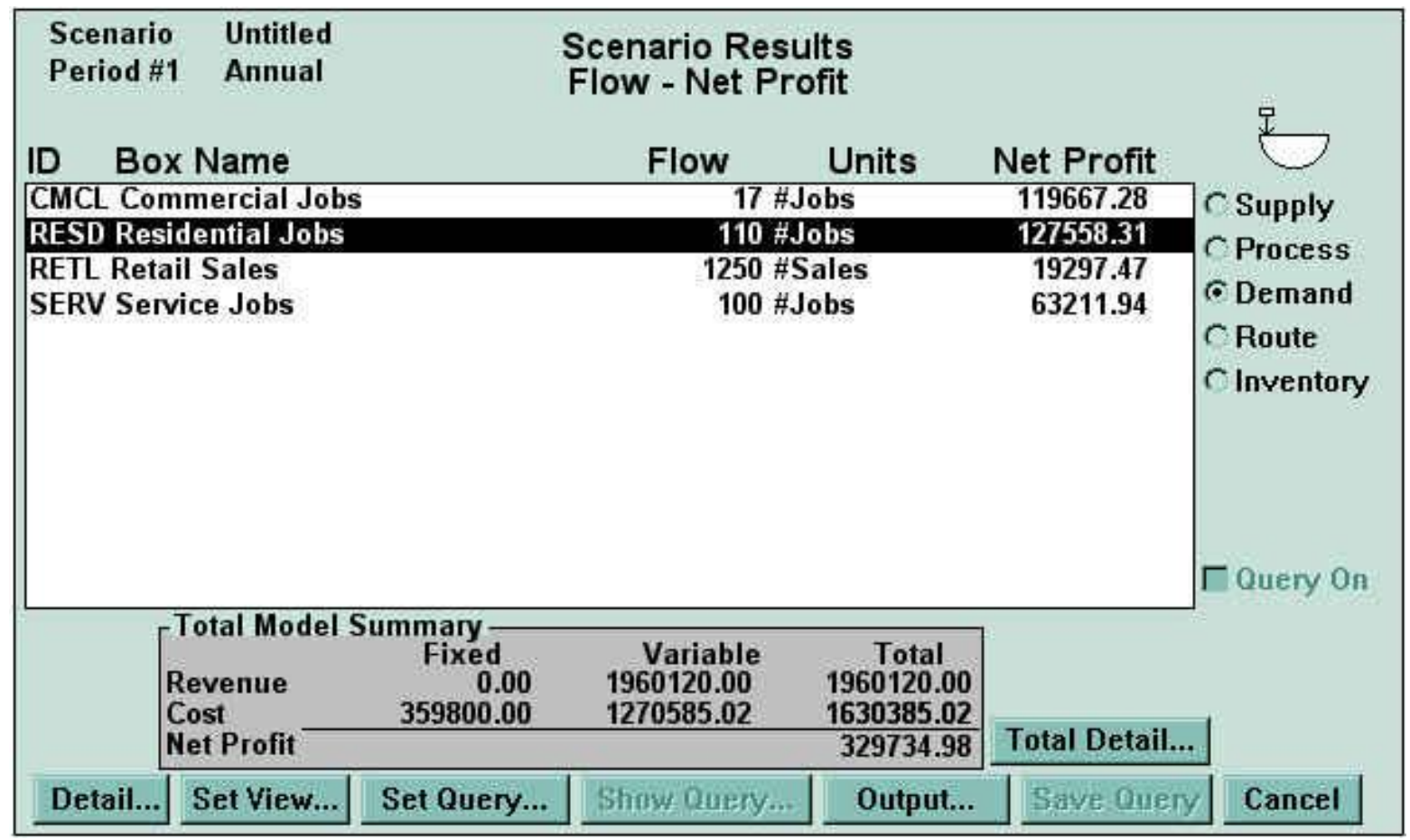


Figure 8

Results After Dropping Retail, Eliminating Direct Retail Costs, and Reallocating Occupancy Space

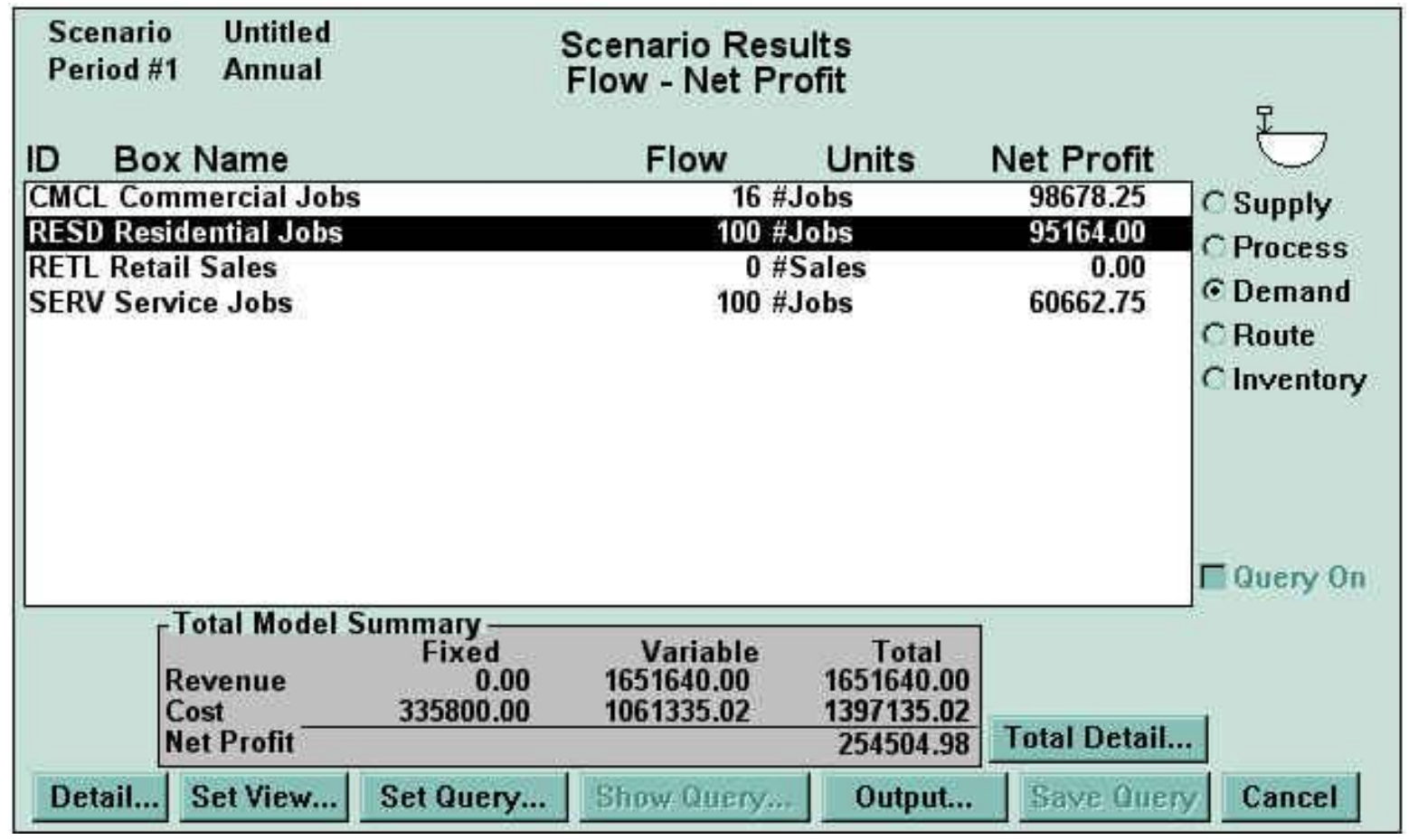

